Products and Services In Practice is provided to readers using text and images from the manufacturer, supplier or distributor and does not imply endorsement by $B D J$ In Practice. Normal and prudent research should be exercised before purchase or use of any product mentioned.

Please send product and services news through to David Westgarth, $B D J$ In Practice via: David.Westgarth@bda.org

\section{Seamless elevated}

The Waterpik Water Flosser is the no.1

Water Flosser brand worldwide.

Accredited by the Oral Health

Foundation and with clinically proven efficacy backed by evidence, there are several models available, so you can help your patients find the right one for them.

There is a device for whitening, and tips that allow the Water Flosser to be used safely and easily around crowns, bridges, orthodontic appliances and dental implants.

The Waterpik Water Flosser will also deep clean periodontal pockets, to reduce patients' risk of developing dental disease.

Once they experience what a hygienic mouth feels like and see how seamlessly the Water Flosser can be incorporated into everyday routines, you can motivate your patients into other preventive practises for better health.

For more information on Waterpik products visit www.waterpik.co.uk.

Book a free Waterpik professional Lunch and Learn for 1 hour of verifiable CPD and a free Waterpik Water Flosser available either face to face or as a webinar - at www.waterpik.co.uk/professional/ lunch-learn/

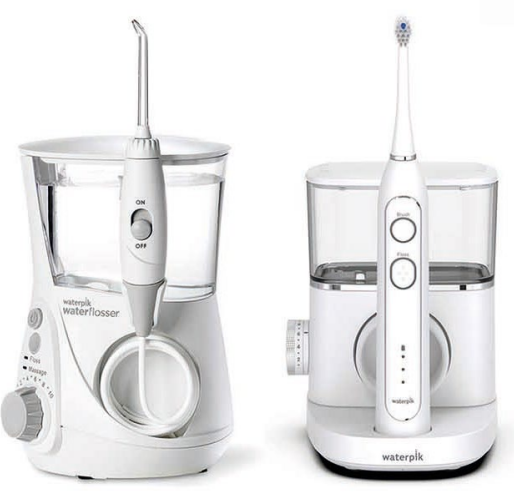

\title{
Here to help with lateral flow tests
}

If you're performing lateral flow tests in your practice to help protect staff and patients against Coronavirus, you need to ensure that these are being disposed of correctly.

The vial, swab and tissue from these tests are considered chemical waste by the government, and as such need to be disposed of in a clear plastic bag and collected by a waste management expert.

Initial Medical is one of the only waste management experts in the UK to have secured the additional capacity needed to collect chemical waste, meaning that they're the perfect choice to guarantee that you're disposing of waste generated by these tests responsibly.

To find out more, visit www.initial.co.uk/ medical or call 08708504045 .

\section{The discreet solution}

Patients want orthodontic solutions that suit their lifestyles. This means that in many cases, patients will be seeking a more discreet solution.

Clear brackets are an option, but what about a device that is virtually invisible?

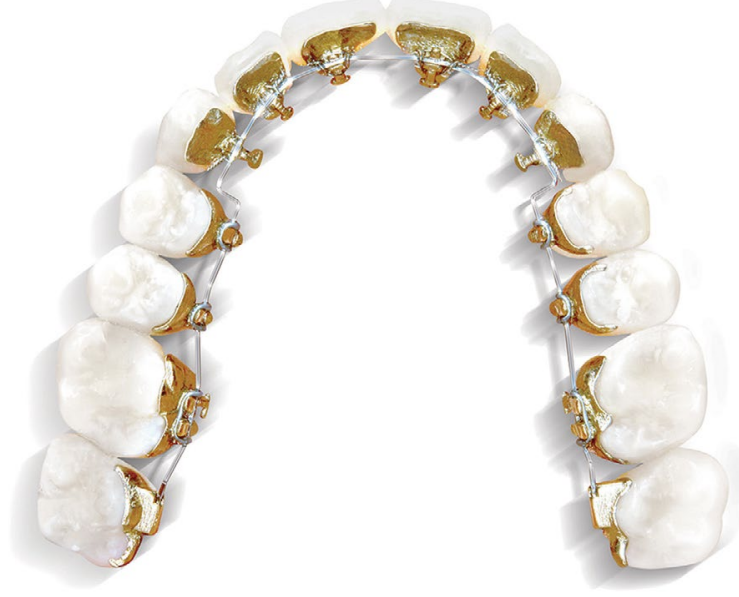

The Incognito Appliance System from $3 \mathrm{M}$ Oral Care is a discreet, tailored solution that allows patients to continue smiling with confidence throughout treatment.

As the device is placed behind the teeth and fully bespoke to each patient, it allows for predictable, aesthetic treatment. Brackets, archwires and bonding trays are crafted to suit the unique oral anatomy of each patient, and with extra features such as rounded brackets, you can ensure ultimate comfort for patients during treatment.

For more information, call 08458734066 or visit www.3m.co.uk/ incognito. 